\title{
DOSSIÊ
}

Sociologias, Porto Alegre, ano 16, no 37, set/dez 2014, p. 24-41

\section{Os novos rumos dos estudos sociais de ciência e tecnologia; continuidade e ruptura na teoria social - implicações para o Brasil e a América Latina}

\section{Resumo}

O artigo procura fazer uma discussão geral a respeito da trajetória dos estudos sociais da ciência e da tecnologia, focalizando, em rápidas passadas, o debate seminal na sociologia da ciência, e os atuais questionamentos, notadamente aqueles trazidos pelo chamado construtivismo. Procura-se argumentar em favor da necessidade de se ampliar a discussão acerca do conteúdo cognitivo no encerramento das controvérsias científicas, muitas vezes negligenciado em algumas abordagens construtivistas. Isso sem negar a importância de tais abordagens na explicitação do conteúdo social presente na ciência e na tecnologia. Conclui-se, levantando alguns pontos para um aprofundamento das implicações de tais reflexões sobre os estudos sociais da ciência e da tecnologia para o contexto da sociedade brasileira e de demais países da América Latina.

Palavras-chave: Sociologia da ciência e da tecnologia. Construtivismo. Conteúdo cognitivo da ciência. Controvérsias científicas.

Universidade de Brasília, Brasília - DF, Brasil. 
The new paths in the social studies of science and technology continuity and rupture in social theory - implications for Brazil and Latin America

\section{Abstract}

This paper makes a general discussion on the trajectory of social studies of science and technology, presenting the seminal debate in the sociology of science and the current questions put in this field, especially those brought by the so-called constructivism. We argue for the need to extend the debate about the cognitive content in the closure of scientific controversies, a content often overlooked in some constructivist approaches. This, however, does not mean to deny the importance of such approaches for exposing the social content involved in science and technology. We conclude by suggesting some topics worth to deepen regarding the implications of such reflections for the context of Brazilian society and other Latin American countries.

Keywords: Science, Technology and society. Constructivism. Cognitive content of science. Scientific controversies.

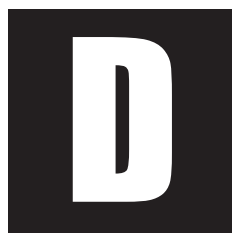

iscutir os rumos seguidos pelos estudos sociais em ciência e tecnologia e focalizar seus novos compromissos para com a sociedade brasileira e demais países da América Latina soa como alvíssara. Nesse sentido, cabe, sim, o aprofundamento teórico e a ampliação dos debates nas ciências sociais e entre estas e outras áreas do conhecimento como a filosofia, a história, a economia, a biologia e assim por diante. Há muito a desmistificar a respeito da natureza e dos compromissos sociais da ciência e da tecnologia.

O debate se dá, principalmente, com as abordagens que se pautam pelo estrito protocolo legado pela Epistemologia, em sua versão clássi- 
ca, ainda hegemônica, em muitos campos do conhecimento científico. É exemplar de tal versão o conjunto de trabalhos do chamado Círculo de Viena, nos idos anos de 1920, cuja linha filosófica ficou conhecida como positivismo lógico. Trabalhos, estes, que marcam rígida separação entre a cognição ou a racionalidade e o mundo social, ao entenderem que a boa ciência é aquela que, basicamente, segue rigorosos procedimentos lógicos e conceituais, sobrevalorizando a importância da matemática e da quantificação na formulação das teorias e dos enunciados científicos. Nessas abordagens, a boa ciência deve estar apartada de todos os tipos de influências, subjetividades, ideologias e interesses de qualquer outra natureza que não a razão e a objetividade.

Esse pensamento, como sabemos, muito influenciou as obras de um dos fundadores da sociologia da ciência, Robert Merton, conquanto, para este, seguindo as pegadas de Max Weber, a cultura e os valores sociais sejam condicionadores das escolhas dos problemas de pesquisa, das opções metodológicas e das preferências teóricas. Condicionam, faz questão de frisar o primeiro autor, mas não devem interferir nos "juízos de realidade", objetivo maior da ciência - produzir conhecimentos empiricamente comprovados e logicamente consistentes. Isto é, dizer da realidade, o mais fielmente possível, aquilo que ela é; em suma, descrevê-la e explicá-la. Nesse caso, o verbo "dever", flexionado na terceira pessoa, é tanto um indicativo do que Merton considera característica da ciência quanto - como apontado por seus críticos, notadamente os da linha construtivista - um imperativo, algo prescritivo e mandatório. De qualquer modo, Merton dá um passo importante no caminho que seguiria a sociologia da ciência, ao apontar a natureza institucional da atividade científica, configurando aquilo que designou o seu ethos. O universalismo, o ceticismo organizado, o desinteresse e o comunismo - aspectos importantes do ethos científico, segundo o autor - precisam ser necessariamente levados em conta 
pelos cientistas e suas comunidades; sem o que, os resultados da ciência e sua cumulatividade estariam seriamente ameaçados. Preocupação ressaltada, sobretudo, pelo temor de que o nazismo, ou o Estado, de um modo geral, pudesse vir a interferir ou a diminuir a autonomia do cientista, movido, ainda de acordo com Merton, pelo exclusivo compromisso com a busca pela verdade. Essa deveria ser a sua obstinação, e nada mais.

Os desdobramentos dessa posição e os questionamentos que ocorreram, principalmente, com a contribuição seminal das obras de David Bloor, Barry Barnes, Harry Collins, Donald A. MacKenzie, e John Henry - propiciando aquilo que ficou conhecido como o Programa Forte em sociologia da ciência, a partir da década de 1970 - levaram a voltarem-se algumas reflexões para o questionamento acerca da natureza das teorias científicas. Isso abriu, ou reabriu, o seguinte questionamento: afinal, o que é uma teoria científica? Era precisamente isto que estava em jogo no debate com a tradição da Epistemologia.

Essa pergunta não é uma que se faz, tipicamente, na sociologia, embora lá encontre repercussão. Depois de percorrer a trajetória clássica da sociologia da ciência - desde Robert Merton, Pierre Bourdieu e Thomas Kuhn, até chegar aos chamados construtivistas, a exemplo de Bruno Latour, Karin Knorr-Cetina, Michel Callon, Steve Woolgar, além dos precursores mencionados anteriormente -, essa questão persistia: o que é uma teoria científica? Vista pelo ângulo dessa última abordagem, uma teoria científica é mera representação social; algo que surge, entre tantas possibilidades, no entrechoque de opiniões, interesses de toda ordem, enfim, numa mistura de valores sociais com condições institucionais, capacidades e recursos humanos e financeiros adequados.

É claro que o questionamento acerca da natureza de uma teoria científica é algo extremamente complexo, principalmente se olharmos a ciência em sua perspectiva histórica como o fizeram, por exemplo, 
Thomas Kuhn, Larry Laudan e Imry Lakatos ${ }^{1}$. Tantos são os exemplos de reviravoltas, mudanças radicais na interpretação e explicação de muitos fenômenos, que somos levados a concordar, em princípio, com essa argumentação historicista. Especialmente em razão da clareza de sua exposição, na obra de Kuhn, ficamos com a sensação de que, realmente, nada mais haveria a dizer a esse respeito. Estava descoberto o "Santo Graal".

Enfim, para Thomas Kuhn, não há como distinguir o que é (ou o que foi) uma teoria verdadeira de outra falsa, ao longo da história da ciência; o que é considerado verdade em um paradigma não o é em outro. Essa discussão é exemplar na obra de Kuhn, ao abordar o que chamou a incomensurabilidade entre os paradigmas - o que só aumenta a dificuldade para uma compreensão a respeito da ontologia das teorias científicas. Para esse último autor, não faz parte da ciência a possibilidade de dizer da realidade aquilo que ela é. Tudo depende, segundo essa interpretação, de um contexto histórico determinado, o qual dá sentido e permite a uma comunidade de cientistas escolher uma e rejeitar outra teoria, não sem muita disputa entre eles - o período revolucionário da ciência -, porém sem saber, de antemão, para que lado irá pender a aprovação generaliza$\mathrm{da}$, o consenso, o novo paradigma. E, assim, sucessivamente, alternando-se momentos de "normalidade" a momentos de "crise", surgidos em decorrência de eventos que não conseguem ser "enquadrados" pelas regras, métodos e modus operandi de determinado paradigma.

\footnotetext{
${ }^{1}$ De acordo com Díez e Moulines (1997), Kuhn, Laudan e Lakatos - três dos principais representantes da escola historicista no campo da Filosofia da Ciência - se apresentam como uma espécie de rebelião contra a tradição dominante nesse campo do conhecimento, seja na vertente carnapiana (referindo-se a Rudolf Carnap), seja na popperiana; tradição esta (a concepção herdada), na obra citada de Díez e Moulines, que apresentava uma imagem muito pobre e totalmente inadequada da dinâmica do conhecimento científico segundo o historicismo. Na interpretação de Díez e Moulines (1997, p. 32), a crítica mais significativa, ainda na divergência com a concepção herdada, é outra, mesmo que mais implícita que explícita, que leva os historicistas a proporem uma noção intuitiva de teoria científica muito mais complexa, ao ressaltar de imediato o caráter excessivamente simplista de teoria, comum tanto a carnapianos quanto a popperianos.
} 
Sociologias, Porto Alegre, ano 16, no 37, set/dez 2014, p. 24-41

Foi nesse mesmo "solo fértil" que brotou e prosperou o construtivismo. Essa abordagem buscou, nos vários programas empíricos de pesquisas, não apenas uma confirmação das teses de Thomas Kuhn, mas enfrentar a discussão, em "pé de igualdade" com a filosofia, particularmente com o seu principal adversário, o chamado realismo.

Aqui, chegamos ao limiar de um debate que precisa ser mais aprofundado. Acompanhando a metáfora de Peter Berger, o sociólogo é aquele personagem que está sempre buscando olhar "pelo buraco da fechadura". Diz-nos o mesmo autor: os mistérios sociais estão sempre por detrás das fachadas.

Voltando à discussão central, é muito interessante o anseio da abordagem construtivista por conhecer e examinar a ciência a partir da "porta dos fundos", ou seja, a ciência em ação, nas palavras de Bruno Latour. Em seu livro com esse título, o autor ambiciona desvendar os tais mistérios sociais que não são revelados de imediato pelo resultado final da atividade científica e pelas teorias formuladas - o que seria, para acompanhar a imagem trazida por Berger, mera fachada da ciência. Nessa ambição, acompanhada por muitos autores da referida abordagem, há, inegavelmente, méritos. Contudo, uma das inquietações que motivou a presente reflexão é o que se entende ser o excessivo peso que a abordagem construtivista passou a dar aos aspectos sociais, na interpretação de como as teorias científicas são construídas; ou, em sua linguagem, em como as controvérsias são estabilizadas. Em outras palavras, nessa abordagem, não sobraria muito espaço para os fatores cognitivos ou racionais.

Parece bastante razoável admitir que nem tudo se resume, no final das contas, à estabilização das controvérsias, aos aspectos sociais - interesses dos indivíduos e de grupos sociais, e as disputas pelo poder, o que inclui crenças de todos os tipos e trajetórias imprevisíveis. O fato de que esses aspectos constituem parte importante da atividade científica - historicamente 
condicionada e moldada por um jogo de interesses, os mais diversos, em busca de se obter a hegemonia em cada campo do conhecimento científico - é bem demonstrado por muitos autores (para citar ao menos um, Pierre Bourdieu), e pela própria linha construtivista. Entretanto, reduzir essa atividade, basicamente, a tais fatores sociais, parece insustentável. Não estou a dizer que o construtivismo não admita a dimensão cognitiva na atividade científica, mas é bem evidente, a julgar pelo conjunto dos trabalhos assentados nessa perspectiva teórico-filosófica, que tal dimensão não mereceu a devida importância; talvez até mesmo para exorcizar o fantasma que imperou e que ainda domina muitos ambientes acadêmicos.

De qualquer modo, sem abdicar de uma posição em favor do argumento em defesa de um conteúdo social para a ciência e para a tecnologia, na linha construtivista, penso que se faz mister avançarmos mais na reflexão ou no resgate do âmbito da cognição, no esforço para compreender a natureza da ciência e de suas teorias, para mais bem situarmos sua relação com o mundo social.

Procurando trilhar nessa direção - e obviamente isso não é uma novidade - entendo que, na aceitabilidade das teorias científicas, devem contar, também, regras e decisões que passam, necessariamente, pelo crivo da razão, pelo tribunal da lógica e da evidência, e por procedimentos e experimentos cognitivamente bem construídos ${ }^{2}$. Admitir isso em nada

\footnotetext{
$\overline{2}$ É interessante observar, em uma das mais citadas obras de Latour (1999), o seu Ciência em Ação, que o autor dedica um capítulo inteiro ao que chama os Tribunais da Razão. Nesse capítulo, ao contrário de tentar enaltecer a lógica e a racionalidade que presidem a ciência moderna, como pode sugerir o título do capítulo, procura desmascará-las, a partir de exemplos, os mais exóticos, em que examina os dois ou mais lados envolvidos em diferentes pendengas, aplicando alguns dos pressupostos do chamado Programa Forte, formulado por Bloor (1976) e por Barnes (1977), como os princípios da simetria e da reflexividade. A ironia de Latour tenta demonstrar que não há um critério objetivo, como uma linha divisória, para separar o âmbito do racional do irracional; o que ele procura concluir é que a ciência e a chamada racionalidade científica são apenas uma dentre outras maneiras, também racionais, de ver o mundo e de (representá-lo e) se expressar.
} 
compromete o principal horizonte aberto pela abordagem construtivista, inegavelmente um avanço na compreensão do fenômeno científico.

A importância da obra de Kuhn é muito reconhecida, mesmo na perspectiva que procura realçar os aspectos propriamente cognitivos da ciência, sobretudo em sua obra intitulada O Caminho desde a Estrutura. A propósito, não apenas Thomas Kuhn, mas, igualmente, Larry Laudan e Imry Lakatos, representantes do historicismo na filosofia da ciência, deram contribuições importantes para ampliar a concepção sobre a natureza das teorias científicas e o modo como se dá sua dinâmica, ao longo do tempo.

Entendem os pós-modernistas, entre os quais se incluem ampla gama de autores, de origens as mais diversas - da filosofia, sociologia, antropologia, história e literatura, por exemplo - serem a razão e a ciência, bem como a tecnologia moderna, responsáveis pelo cerceamento das liberdades e pelo aumento considerável da dominação, mundo afora. Ademais, procuram combater essa forma hegemônica de conhecimento, identificada com a ciência moderna e experimental. E, nesse sentido, a obra de Kuhn também encontra espaço de acolhimento muito compreensível, pois elimina de sua narrativa a ideia de conhecimento universalmente objetivo e verdadeiro, tão cara para o núcleo central do chamado realismo; o que, enfim, acaba por reforçar as concepções relativistas a respeito da ciência, de certo modo muito acolhidas pelos pós-modernistas.

Em que pesem tais contribuições, legadas ao debate pela tradição historicista, a presente reflexão pretende se colocar no campo oposto ao do relativismo a respeito da ciência. O que não significa estar alinhado, automaticamente, ao realismo, em sua forma mais clássica. Pretendo argumentar, neste ponto, que a crítica à ciência moderna não se esgota em sua mera rejeição, como pretendia, por exemplo, Herbert Marcuse, em meados dos anos de 1960, ao dirigir comentários contundentes contra o que chamou o operacionalismo e o projeto de dominação da ciência 
e da técnica modernas, enfim, à vitória do pensamento unidimensional, em detrimento do pensamento dialético, rebelde e transformador. Isso está muito bem desenvolvido, como sabemos, em sua obra, A ideologia da sociedade industrial; o homem unidimensional, que também muito inspirou os movimentos da chamada contracultura e o pós-modernismo. Contudo, ainda que se aceitem muitas de suas premissas e sua aguda perspicácia na identificação dos problemas envolvidos na formação de uma consciência crítica, no contexto avançado do capitalismo, suas principais conclusões são tão controversas hoje como o foram à época de sua formulação - controvérsia evidenciada no debate gerado entre autores próximos à sua linha de reflexão, na chamada Escola de Frankfurt, especialmente com Jürgen Habermas.

A abordagem construtivista, embora incluída por muitos autores entre os pós-modernos (tese contestada, por exemplo, no livro de James Robert Brown, Who Rules in Science?), também segue na esteira dos argumentos de Thomas Kuhn. Ao defenderem a linha de que as teorias científicas são basicamente resultados de contingências e dependentes do arbítrio humano, representantes dessa abordagem aproximam-se fortemente do enfoque kuhniano. É importante ressaltar que o próprio Kuhn muito se incomodava com o que entendia ser uma excessiva simplificação de sua discussão acerca da verdade, ao se contrapor, por exemplo, ao Programa Forte, na última obra citada. Para esse autor, a verdade é parte da atividade científica e deve ser sempre buscada. O que não significa, segundo ele, ser uma descrição fiel da realidade, tampouco algo absoluto e universal; ao contrário, depende de um contexto histórico e social específico.

Desmistificar a ciência, retirar seu manto de algo "sagrado", e descrevê-la como um conhecimento qualquer - no mesmo nível, tão racional e tão irracional, tanto um quanto outro -, como um "consenso" estabelecido entre determinados interlocutores que partilham crenças e convicções, é 
o que buscam os autores construtivistas. Há muitas divergências também entre estes, como a estabelecida, por exemplo, entre Harry Collins e Bruno Latour ou Michel Callon a respeito do entendimento do que é social para um e para outros. Como bem sabemos, para Latour, não há sequer demarcação necessária entre atores humanos e não humanos, ao contrário do que defende o primeiro desses autores. Mas, as teses construtivistas fundamentais - notadamente as de que o conhecimento é apenas uma representação da realidade, jamais uma descrição fiel do mundo, seja este físico ou social, colocadas em oposição ao realismo, na filosofia da ciência - são compartilhadas por todos aqueles que se identificam com essa corrente. Talvez esse seja o "nó górdio" da disputa, o que está, de fato, em questão, como assinala lan Hacking, em seu provocativo trabalho The Social Construction of What? Neste, o autor afirma que suas questões contra os construtivistas são, na verdade, determinadas barreiras de natureza filosófica.

Essas considerações reforçam a necessidade de se examinar, mais de perto, o debate realismo versus antirrealismo na filosofia da ciência, no qual se verificam mais claramente os aspectos da controvérsia entre a linha construtivista e a do realismo. Algo que, de um lado, tornaria evidentes os argumentos construtivistas e os realistas, ao insistirem, estes últimos, na busca do que consideram conhecimentos comprovadamente válidos, objetivos e verdadeiros (ou aproximadamente verdadeiros).

No exame do debate realismo versus antirrealismo, não se encontram apenas pólos opostos. Ao contrário, dois autores, por exemplo, se destacam ao assumirem uma posição realista, porém sem deixarem de considerar o imbricamento da ciência com os valores sociais. Trata-se de James Robert Brown (com a obra mencionada anteriormente) e de Philip Kitcher, com o seu Science, Truth, and Democracy, os quais se identificam com um realismo que consideram crítico ou modesto. Ou seja, embora com enfoques diferentes, reconhecem o entrelaçamento entre valores so- 
ciais e os fatos e as teorias científicas - mais, entre a política e a ciência - confrontando teses importantes a esse respeito, como a linha adotada por Max Weber, em Ciência e Política; duas vocações. Entretanto, Brown e Kitcher não abrem mão da ideia de que os conhecimentos almejados pela atividade científica resultem em teorias verdadeiras ou aproximadamente verdadeiras. A busca da articulação entre posições aparentemente extremas, nesse debate, e do estreitamento da ciência com a política, no contexto contemporâneo, seja no plano da realidade concreta, seja no das formulações teóricas ou filosóficas a esse respeito é algo muito original na obra desses autores.

Enfim, o debate entre essas duas grandes e bem diversificadas correntes da filosofia da ciência - entre realistas e antirrealistas - está longe de se exaurir em perspectivas muito doutrinárias, seja em favor de um lado ou de outro. Esse ambiente intelectual, bastante controverso, reflete, em larga medida, os múltiplos movimentos de afirmação de identidade e de busca de padrões mais universais para reger a conduta humana e as ações políticas no quadro atual da globalização; ou seja, reflete os próprios dilemas da nossa sociedade, em ritmo crescente de integração e de padronização, ao mesmo tempo em que se fragmenta e se confronta em múltiplos campos. Localismo e universalismo é, assim, um dilema também presente na discussão entre realismo e antirrealismo. Nesse sentido, afirmam Stuart Brock e Edwin Mares, em seu livro Realism and Anti-Realism, publicado em 2007,

Muito poucos de nós somos antirrealistas globais; bem como muito poucos de nós somos realistas globais [...]; ou seja, a maioria de nós é realista sobre algumas entidades, mas antirrealista local sobre tantas outras (Brock; Mares, 2007, p. 10).

Procurando aprofundar na argumentação em favor da ideia de ampliar o espaço de discussão sobre a dimensão cognitiva da atividade científica, a premissa básica é que a convivência de modelos teóricos com afirma- 
ções muito diferentes entre si, ou opostas, não nega a possibilidade de que se estabeleçam enunciados verdadeiros ou aproximadamente verdadeiros, e que as entidades as quais se referem também os sejam, como os elétrons, as bactérias, as ondas eletromagnéticas, os movimentos sociais, a ascensão social e o lucro, por exemplo. Em suma, o encerramento das controvérsias não se deve apenas, e também não se sabe a priori em que medida, ao arbítrio humano, ou ao mundo social; mas, igualmente, e a depender de uma circunstância ou outra, em maior ou menor peso, a critérios racionais, objetivos e bem estabelecidos, do ponto de vista cognitivo.

Nesse ponto, gostaria de chamar a atenção para a necessidade de envidarmos mais esforços em pesquisas empíricas que possam mais bem aquilatar o peso de um componente ou de outro, do cognitivo ou do social (dos elementos pragmáticos ou dos volitivos), no encerramento de diferentes controvérsias científicas. Outro aspecto a ressaltar é a necessidade de aprofundarmos a compreensão a respeito da influência da tecnologia, seja no encerramento de tais controvérsias, seja na abertura de novas. Em resumo, é muito importante que avancemos nesse debate, sem perdermos o foco e as importantes conquistas obtidas nos últimos trinta anos, na sociologia da ciência. Grosso modo, o mundo social jamais deveria ingressar no processo de elaboração e justificativa dos fatos e das teorias científicas; para os seus defensores, a realidade social é um mundo à parte ao dos fatos cientificamente comprovados, os quais, basicamente, devem seguir regras claras, métodos bem estabelecidos, e se pautar, sobretudo, pelas evidências.

Entretanto, nesse mesmo "pavilhão" em que se abrigam cientistas e filósofos, também passam muitas outras pessoas. É o público que tem acesso ao "prédio" (da ciência, metaforicamente falando), e que o procurou por alguma razão. Num mundo em que ciência, tecnologia e informação estão por toda parte, nos celulares, em novas vacinas, nos novos produtos para a alimentação e em muitas e muitas telas - de computadores, de televisores, 
de aparelhos para medir a pressão, de jogos eletrônicos portáteis e por aí afora - o grande público - de consumidores, empresários, estudantes, operários, profissionais liberais, políticos, mães, pais, educadores, jovens, idosos e de tantas e tantas categorias que compõem as sociedades nesse início de século - certamente também deve fazer parte deste debate.

Isso significa que também é muito importante refletir sobre como tantas e tão variadas formas de manifestação da vontade coletiva e individual passam a se relacionar com a ciência e a tecnologia contemporâneas. Afinal, "quem governa a ciência, hoje?" pergunta-nos e convida-nos a refletir o trabalho citado de Brown. E como deve ser governada? Assim, ao buscar refletir sobre a natureza da ciência e sobre as grandes controvérsias em torno dela, nesta oportunidade, gostaria de, antes de encerrar, ressaltar a necessidade de mais enveredarmos em questões do mundo concreto, as das ações práticas e da política ligadas à ciência e à tecnologia. Nesse percurso, é fundamental o exame cuidadoso daquilo que ficou conhecido, na literatura especializada, como as "guerras da ciência" (entre correntes realistas e determinadas linhas construtivistas) ${ }^{3}$.

\footnotetext{
${ }^{3}$ Essa expressão foi atribuída à forte divisão que passou a se estabelecer, desde o final dos anos de 1990, entre os adeptos dos Estudos Sociais da Ciência e da Tecnologia (notadamente a abordagem construtivista na Sociologia da Ciência e da Tecnologia, além de uma miríade de outros autores, pós-modernos, em sua crítica aos ideais iluministas de uma razão libertadora, na contestação do que consideram o imperialismo da ciência no mundo hodierno, como já comentado) e os realistas científicos, entre estes, Alan Sokal. Este último autor deu a partida a uma intensa polêmica entre esses dois grandes lados ao publicar, em 1996, um famoso artigo, um trote, em um renomado periódico, que dava grande vazão às novas abordagens provenientes do lado considerado menos ortodoxo de entendimento do que vem a ser a ciência atual. O "hoax" (como ficou conhecido na literatura), pregado por Sokal, procurava mostrar que, entremeando ideias desconexas, termos da moda e com grande apelo junto aos críticos da ciência positivista, a eventuais argumentos bem construídos, ou seja, algo no fundo sem o menor sentido, objetivamente falando, conseguiria espaço para uma publicação, o que, de fato, ocorreu. Queria provar que, para o grupo dos pós-modernos e dos relativistas, incluindo nesses alguns da linha construtivista, qualquer coisa poderia valer, mesmo que sem qualquer sentido ou coerência. Propunha uma narrativa como qualquer outra, como, igualmente, faziam aqueles que considerava seus principais alvos de crítica, segundo seu entendimento. Isto é, queria mostrar que os defensores de uma nova interpretação do que é a ciência e de
} 
Esse fato atingiu em cheio os brios dos contendores e passou a gerar pilhas e pilhas de artigos publicados, nos mais diferentes jornais, em periódicos científicos e em vários anais de congressos de associações científicas. A polêmica se intensificou, levando a que ambos os lados buscassem fortalecer seus pontos de vista e suas orientações teóricas e filosóficas. Com isso, ganham não apenas os interessados diretamente no assunto - cientistas, filósofos, intelectuais, de modo geral - mas também o grande público.

Que ciência é esta que praticamos no início do século XXI? Que tecnologia é esta e a que se destina? Enfim, que relação se pode estabelecer entre ciência, verdade e sociedade? Certamente são questões que estão muito além dos limites deste trabalho. Como nos diz Kitcher, a ciência põe, a sociedade propõe. Importa, neste momento, perceber determinadas limitações nos enfoques que nos foram legados e que ainda cumprem papel relevante na construção do entendimento a respeito da ciência e da tecnologia no mundo de hoje, bem como o que apontam como novas alternativas, sem o apelo à inevitabilidade da destruição, tampouco ao voluntarismo. Parafraseando Marx, somos nós que construímos a nossa história, mas a fazemos dentro de limites estruturais e históricos bem definidos.

Ter claros esses limites, bem como as possibilidades para novos caminhos e desafios, é parte do trabalho do sociólogo, quando não, atuar diretamente em ações concretas, seja como cidadão ou como membro de comunidades científicas, visando à construção de uma sociedade mais justa e consciente de seus direitos. As questões anteriores, e muitas outras, ligadas, não só à ciência e à tecnologia, mas também a vários outros temas como os das endemias, das ameaças ao ambiente e aos direitos à

como ela é feita - os heterodoxos e construtivistas, que negam a verdade objetiva das teorias científicas, e para quem tudo são representações, sujeitas ao arbítrio e a fatores meramente contingentes, sem fundamento racional - estavam enredados em grandes discussões, sem qualquer base ou fundamento; em suma, em mera retórica. 
liberdade de expressão e de manifestação, não restritos ao circuito científico-tecnológico, emergem com vigor renovado, após longo período de latência e conformismo, entrevisto pela chamada Teoria Crítica como um fenômeno aparentemente irreversível, uma vez que ciência e tecnologia teriam se tornado fundamento de legitimação do contexto atual do desenvolvimento capitalista. Essa renovada inquietação percebida, crescentemente, nas diferentes manifestações sociais, mundo afora, e que atingem também o mundo científico e o da produção de novas tecnologias, parece contrariar as afirmações tão peremptórias de determinado autores, como Max Horkheimer, Theodor Adorno, Walter Benjamin e Herbert Marcuse a respeito da alienação proporcionada pelo novo aparato científico-tecnológico; e por que não lembrar, também, do quadro sombrio traçado por Martin Heidegger em seu questionamento sobre a moderna tecnologia e seu "destino"?

Os novos acontecimentos, trazidos pelo próprio desenvolvimento científico-tecnológico - novas biotecnologias, novos materiais, tecnologias de informação e comunicação - se, por um lado, mostram a que ponto podemos chegar no anseio do controle sobre a natureza, os indivíduos e grupos sociais, por outro, propiciam - justamente pelo teor de seus impactos não só econômicos, mas, sobretudo, sociais - novos e relevantes questionamentos. Entre esses, estão os referidos aos rumos da ciência e da tecnologia, e como estas formas importantes de conhecimento podem proporcionar a superação de persistentes problemas que atingem as sociedades e os menos favorecidos. A ciência é instada a rever seus dogmas iniciais e a buscar, além de sua ética da convicção, nas palavras de Max Weber, outra ética, a de responsabilidade e de maior comprometimento com o futuro e o bem estar, nas sociedades. O que significaria estreitar os laços da ciência com a política.

Com essa preocupação, se devem olhar as realidades da América Latina. Nesse sentido, temos caminhos promissores no campo do avanço 
Sociologias, Porto Alegre, ano 16, no 37, set/dez 2014, p. 24-41

científico e tecnológico, mas, igualmente, uma grande agenda de questões fundamentais a resolver que resistem ao longo de nossas histórias, e que envolvem, sobretudo, os menos favorecidos. Isso importa considerar no debate a respeito do papel da ciência e da tecnologia no mundo contemporâneo.

Em nosso caso, a sociedade brasileira, ao mesmo tempo, é economia forte, com grande potencial, e encerra grandes enclaves de pobreza, analfabetismo, sérias desigualdades, injustiças de toda ordem e outros males que herdou de uma história fortemente excludente e predatória. Com efeito, para nós, longe de ser suficiente tentar compreender os aspectos mais abstratos, inegavelmente relevantes, de como se constituem as teorias científicas ou de que modo estas são aceitas por seus praticantes e pelo público mais especializado, para podermos separar conhecimento objetivo de ficção, precisamos encontrar meios adequados para dirigir todo esse esforço e o resultado do trabalho árduo de muitos cientistas em prol da superação dos problemas sociais e econômicos recorrentes.

Ou seja, se, para qualquer sociedade que resolveu suas principais questões no plano social é importante ter claro o que é uma well-ordered science - segundo Philip Kitcher, algo mais que a pura descoberta da verdade, mas a sua organização para a superação de importantes problemas sociais -, para os brasileiros, e para muitos povos latino-americanos, essa necessidade parece mais premente.

Gostaria de encerrar esta discussão comentando um ou dois trechos da obra citada de Brown, que tem muito a ver com as últimas considerações, e, grosso modo, com o espírito que motivou a presente reflexão. Primeiramente, uma livre tradução de um trecho, à página 25 do livro citado, diz-nos:

A ciência, sem dúvida, tem feito muito para criar essa riqueza [referindo-se aos resultados alcançados nos governos de Reagan e Bush, nos Estados Unidos, e de Thatcher, na Inglaterra, bem como em outros países do chamado primeiro

http://dx.doi.org/10.1590/15174522-016003702 
mundo, no final do século passado]. Porém [pergunta-se], o que a ciência tem feito com sua distribuição? [grifo no original]. [...]. A sociobiologia tem sido neutra nisso tudo? As ciências econômicas e a sociologia têm sido alheias? (Brown, 2001, p. 25)

Ao cobrar maior envolvimento das ciências de hoje, incluindo a economia e a sociologia, na distribuição das riquezas, o autor enfatiza que isso seja feito sem abrir mão da possibilidade de se obterem conhecimentos objetivos e devidamente comprovados. A esse respeito, cita Michael Albert, conhecido editor de um periódico de esquerda que publicou determinados artigos e comentários de Noam Chomsky, nos quais esse autor teria aplaudido o famoso trote aplicado por Sokal, bem como seus motivos, na guerra das ciências. Para o editor, a esquerda não possui nenhuma arma importante em suas mãos, a não ser a lógica e a racionalidade. Então, por que abandoná-las?

Em suma, procurar identificar as bases de sustentação de uma ciência solidamente constituída, objetiva, cujos resultados sejam racionalmente justificados e devidamente comprovados empiricamente; reconhecer isto como uma possibilidade histórica real em meio a permanentes controvérsias; e evidenciar a necessidade de que, ao mesmo tempo, ela seja permeada por novos valores e compromissos morais em prol da superação de importantes problemas que afligem às sociedades são os objetivos centrais que busquei com esta reflexão.

Michelangelo Giotto Santoro Trigueiro. Sociólogo de formação básica, mestre e doutor em sociologia. Pós-doutor pelo Instituto de Filosofia, Lógica e Filosofia da Ciência, da Ludwig-Maximilians-Universität, em Munique (Alemanha), pelo Centre for Social and Economic Research on Innovation in Genomics (Innogen), na Inglaterra, e um terceiro pós-doutorado pelo Departamento de Política Científica e Tecnológica da Unicamp. Professor associado IV da Universidade de Brasília. michelangelo.trigueiro@gmail.com 
Sociologias, Porto Alegre, ano 16, no 37, set/dez 2014, p. 24-41

\section{Referências}

1. BARNES, B. Interests and the Growth of Knowledge. London: Routledge \& Kegan Paul, 1977.

2. BROCK, S.; MARES, E. Realism and Antirealism. McGill-University Press, Montreal \& Kingston, 2007.

3. BLOOR, D. Knowledge and Social Imagery. Chicago: University of Chicago Press, 1976.

4. BROWN, J. R. Who Rules in Science: An Opinionated Guide To The Wars. Cambridge: Harvard University Press, 2001.

5. COLLINS, H. M.; EVANS, R. The Third Wave of Science Studies: Studies of Expertise and Experience. Social Studies of Science, London, v. 32, n. 2, p. 235296, 2002.

6. DÍEZ, J. A.; MOULINES, C. U. Fundamentos de Filosofía de la Ciencia. Editorial Ariel S.A., Barcelona, 1997.

7. HABERMAS, J. Ciência e Técnica como Ideologia. In: Os Pensadores. São Paulo: Abril Cultural, 1980.

8. HEIDEGGER, M. The Question concerning Technology; and other essays. New York: Harper Torchbooks, 1977.

9. KITCHER, P. Science, Truth, and Democracy. Oxford: Oxford University Press, 2001.

10. KUHN, T. Estrutura das Revoluções Científicas. São Paulo: Perspectiva, 1978.

11. LATOUR, B. Ciência em ação. São Paulo: Unesp, 2000.

12. LAUDAN, L. A Confutation of Convergent Realism. Philosophy of Science The Central Issues. New York, W.W. Norton \& Company, 1998.

13. LAUDAN, L. Demystifying Underdetermination. Philosophy of Science The Central Issues, New York, W.W. Norton \& Company, 1998.

14. MERTON, R. Sociologia; teoria e estrutura. São Paulo: Editora Mestre Jou, 1968.

15. TRIGUEIRO, M. G. S. Formação de Recursos Humanos em Áreas Estratégicas de Inovação no Brasil: contribuição para a construção de uma agenda. In: Centro de Gestão e Estudos Estratégicos. (Org.). Formação de Recursos Humanos em Áreas Estratégicas de Ciência, Tecnologia e Inovação. 01 ed. Brasília: CGEE, 2010.

16. TRIGUEIRO, M. G. S. Sociologia da Tecnologia; bioprospecção e legitimação. São Paulo: Centauro, 2009.

Recebido em: 22/05/2014

Aceite final: 15/07/2014

http://dx.doi.org/10.1590/15174522-016003702 